\title{
Gambling disorder in adolescents: prevalence, new developments, and treatment challenges
}

This article was published in the following Dove Press journal:

Adolescent Health, Medicine and Therapeutics

\author{
Georgios D Floros \\ 2nd Department of Psychiatry, \\ Medical School, Aristotle University of \\ Thessaloniki, Thessaloniki, Greece
}

\begin{abstract}
Research on adolescence gambling over the past twenty years has revealed significant incidence and prevalence rates and highlighted the possible negative effects on an adolescent's well-being. Several risk and protective factors have also been identified. Over the course of the past few years, technological advances have heralded the advent of new avenues for gambling as well as new opportunities to gamble without any direct monetary exchange. This review article examines those established trends as well as the new issues that we are faced with, in order to accurately portray the current challenges in research, prevention, and treatment.
\end{abstract}

Keywords: adolescence, gambling disorder

\section{Introduction}

Adolescent gambling has come into focus since the seminal paper of Lesieur and Klein ${ }^{1}$ reported high percentages of both incidence and prevalence rates, for some form of gambling, among New Jersey high-school students. After a multitude of prevalence studies in the space of twelve years, the National Research Council concluded, in 1999, that the proportion of pathological gambling among adolescents in the US could be more than three times that of adults. ${ }^{2}$ Compared to the timeframe of those early research findings, gambling practices and opportunities have evolved to the point where they are widely available and viewed as a socially acceptable form of entertainment, while becoming increasingly attractive to young people (e.g., social casino gambling, ${ }^{3}$ online gambling, ${ }^{4}$ mobile gambling, ${ }^{5}$ gambling within online video games, ${ }^{6}$ simulated gambling within other forms of entertainment ${ }^{7}$ ). This leads to unique challenges in defining what constitutes gambling, ascertaining its prevalence and providing effective treatment options. The fact that it remains a prohibited activity complicates and attenuates measurement issues, yet its reported worldwide prevalence indicates that it remains a serious mental health challenge.

\section{Classification and research}

As with adult gambling behavior, we can perceive adolescent gambling behavior forming a continuum that ranges from non-gambling to occasional/recreational/nonproblematic/social gambling to at-risk gambling to problem/pathological/compulsive or disordered gambling, as is the current term on the fifth edition of the Diagnostic and Statistical Manual of Mental Disorders (DSM-5). ${ }^{8}$ Similar to adults, these excessive forms of gambling typically result in severe psychosocial, behavioral, economic,
Correspondence: Georgios D Floros 2nd Department of Psychiatry, Aristotle University of Thessaloniki, 196 Langada Street, Thessaloniki 564 29, Greece

Tel +306944324565

$\mathrm{Fax}+302312203122$

Email georgefloros@gmail.com 
inter-personal, and legal difficulties. A 2016 review of the literature accepts that between $4 \%$ and $8 \%$ of adolescent gamblers are experiencing significant gambling-related problems. ${ }^{9}$ Those include various psychosocial issues, poor academic performance, intrafamilial conflict, economic hardship, difficult peer relationships and social exclusion, diffuse and multiple mental health issues including increased rates of suicide ideation and attempts, drug and alcohol use, and a host of delinquent, legal and criminal problems. ${ }^{10-15}$

\section{Estimation of adolescent gambling prevalence}

Turning to reported prevalence estimates on adolescent gambling, we find a large variation depending on the country, measuring instrument, and target sub-population. The vast majority of relevant studies are population-based crosssectional studies carried out with the aid of a diagnostic questionnaire. There is a number of diagnostic, paper-pen questionnaires validated throughout the world, including the South Oaks Gambling Screen Revised for Adolescents (SOGS-RA), ${ }^{16}$ Diagnostic and Statistical Manual-IV adapted format for Juveniles (DSM-IV-J) ${ }_{17}^{17} \mathrm{Lie} /$ Bet Scale ${ }^{18}$ Canadian Adolescent Gambling Inventory (CAGI),${ }^{19}$ and the Gamblers Anonymous Twenty Questions (GA20), ${ }^{20}$ the most frequent of which are the SOGS-RA and DSM-IV-J. Those measures are self-report instruments that have been directly adapted from adult versions. The benefit of a dual version of the same instrument is the ability to compare data between gamblers in late adolescence and early adulthood in a population level, and also to monitor the trajectory of an individual gambler's gambling behaviors from adolescence to adulthood, in clinical practice. The drawback is that the questionnaires focus on behaviors compatible with the established definition of gambling as a disorder implicitly involving money wagers, loss of money, or financial assistance by others in order to gamble. As we shall see later, this may not be always the case.

\section{Worldwide prevalence rates of problem gambling}

A recent systematic review of published national studies up to 2014 reported that problem gambling prevalence rates in North America ranged from $2.1 \%$ to $2.6 \%$ and in Oceania from $0.2 \%$ to $4.4 \%$, while in Europe, problem gambling prevalence rates ranged from $0.2 \%$ to $12.3 \%$. Since then more data were published from all across the globe. A literature review of newer data from these past five years, since 2014, was carried out by running an NLM/PubMed, PsychINFO, and Scopus query on the terms most frequently employed (gambling AND adolescent/youth/students/pupils/children/ old). Relevant studies containing prevalence data are presented in Table 1.

The large variance among those results highlights the difficulties in accurately measuring the phenomenon. The validity of the results is hard to ascertain since it depends to a large extent on the willingness of the subject to answer candidly, given that the issue is a sensitive one; this in turn is relative to the recruitment method and incentive to participate. Furthermore, studies may differ significantly as to their inclusion criteria and target populations. Those methodological concerns contribute to results that vary significantly from country to country, or between different studies in the same country.

\section{Favored forms of gambling among adolescents and the impact of the Internet}

Although adolescents do indulge in forms of gambling that are popular among adults (including games of cards like poker, sports wagering, dice, and board games, betting on games of personal or peer skill, buying lottery tickets, wagering or placing bets with a bookmaker), there has been a steady increase in adolescents turning to novel forms of gambling via the Internet. ${ }^{4,21,22}$ Typical factors that weigh upon the choice of the particular gambling activity include local availability and accessibility, gender (males may favor sports gambling more compared to female adolescents), age (older adolescents are more likely to engage in casino and machine gambling, poker, and online gambling), cultural ethnicity, and socioeconomic status. ${ }^{9,23-25}$ Additionally, adolescents' choice of gambling games differs from adults, not only because gambling at this age is illegal, as it was always the case, but also because there is a technological generation gap between the older generations and the current one; digital natives, as the younger generation is called due to them being born in a world where digital communication and entertainment is the norm, ${ }^{26}$ are by definition exposed to a new array of gambling opportunities. Those gambling opportunities defy current classification attempts and cast a doubt as to the accurate estimation of the prevalence of gambling as a whole. They include both commercial and simulated gambling, the difference of the latter being that there are no direct monetary gains and typically no fees required to enter the gambling game.

\section{Commercial and simulated gambling}

Gambling opportunities may or may not include gambling with actual money and can thus be harder to study and 
Table I Adolescent gambling studies with prevalence data since 2014

\begin{tabular}{|c|c|c|}
\hline Author and date & Sample & Prevalence \\
\hline $\begin{array}{l}\text { Wong and So } \\
(2014)^{69}\end{array}$ & $\begin{array}{l}1,004 \text { students in Hong } \\
\text { Kong, aged } 12-19 \text { years }\end{array}$ & $\begin{array}{l}5.7 \% \text { and } 22.9 \% \text { of the Internet gamblers could be classified as at-risk gamblers and pathological } \\
\text { gamblers; online gamblers are } 1.5 \text { and } 3.2 \text { times more likely to develop pathological and at-risk } \\
\text { gambling }\end{array}$ \\
\hline Lee et al $(2014)^{70}$ & $\begin{array}{l}\mathrm{N}=25,456 \text { high-school } \\
\text { students, US }\end{array}$ & $\begin{array}{l}\text { One-third }(n=8,3 \mid 8) \text { reported lifetime gambling, and } 31 \% \text { of the gamblers experienced } \\
\text { gambling problems. Being male and alcohol, marijuana, and non-medical prescription drug use } \\
\text { were associated with twice the odds of gambling }\end{array}$ \\
\hline $\begin{array}{l}\text { Castren et al } \\
(2015)^{71}\end{array}$ & $\begin{array}{l}\mathrm{N}=988 \text { Finnish adolescents, } \\
\text { aged } 12-15 \text { years }\end{array}$ & $51.6 \%$ of the respondents had gambled and $7.9 \%$ were identified as at-risk/problem gamblers \\
\hline $\begin{array}{l}\text { Floros et al } \\
(2015)^{72}\end{array}$ & $\begin{array}{l}2,684 \text { Greek students aged } \\
12 \text { and } 15 \text { years }\end{array}$ & $\begin{array}{l}2.5 \% \text { of the total student sample and } 13.8 \% \text { of those who had had gambling experience } \\
\text { demonstrated problem gambling. Gamblers presented with lower school achievement and } \\
\text { related expectations while scoring consistently higher on measures of Internet addiction, } \\
\text { parental bonding, and psychopathology }\end{array}$ \\
\hline $\begin{array}{l}\text { Hanss et al } \\
(2015)^{73}\end{array}$ & $\begin{array}{l}N=2,059 \text { Norwegian } \\
\text { I7-year olds }\end{array}$ & $\begin{array}{l}1.5 \% \text { were moderate risk gamblers and } 0.2 \% \text { had experienced lifetime gambling problems } \\
\text { (problem gambling). Incidence during the month was } 15.7 \% \text { for low risk, } 5.8 \% \text { for moderate } \\
\text { risk, and } 0.9 \% \text { for problem gambling }\end{array}$ \\
\hline $\begin{array}{l}\text { Räsänen et al } \\
(2015)^{74}\end{array}$ & $\begin{array}{l}N=1,01,167 \text { Finnish } \\
\text { students aged } 14-16 \text { years }\end{array}$ & $\begin{array}{l}\text { The risk of gambling on } \mathrm{I}-2 \text { days a week was eight times as high among boys as among girls and } \\
\mathrm{I} .6 \text { times as high among ninth graders as among eighth graders. Even infrequent gambling was } \\
\text { associated with different problem behaviors }\end{array}$ \\
\hline $\begin{array}{l}\text { Fröberg et al } \\
(2015)^{75}\end{array}$ & $\begin{array}{l}N=4,358 \text { Swedes aged } \\
16-24 \text { years }\end{array}$ & $\begin{array}{l}\text { Incidence proportion of a first episode of problem gambling among } 16-24 \text {-year-olds was } 2.26 \% \text {, } \\
\text { three times lower among females }\end{array}$ \\
\hline $\begin{array}{l}\text { Cook et al } \\
(2015)^{51}\end{array}$ & $\begin{array}{l}N=4,85 I \text { Canadians, } \\
\text { grades } 7-12\end{array}$ & $\begin{array}{l}2.8 \% \text { of the students surveyed categorized as problem gamblers. The odds of problem gamblers } \\
\text { reporting mental distress, a suicide attempt, and delinquent behaviors were higher compared to } \\
\text { other students }\end{array}$ \\
\hline $\begin{array}{l}\text { Canale et al } \\
(2016)^{76}\end{array}$ & $\begin{array}{l}\mathrm{N}=14,778 \text { Italian } \\
\text { high-school } \\
\text { students }\end{array}$ & $\begin{array}{l}\text { Problem gambling prevalence rate was } 4.0 \% \text { while the rate among online gamblers was five } \\
\text { times higher at } 21.9 \% \text {; less than } 10 \% \text { of non-online gamblers were classified as at-risk gamblers, } \\
\text { whereas more than } 20 \% \text { of online gamblers were classified as at-risk gamblers }\end{array}$ \\
\hline $\begin{array}{l}\text { Elton-Marshall } \\
\text { et al }(2016)^{77}\end{array}$ & $\begin{array}{l}\text { 10,035 Canadian students, } \\
\text { grades } 9-12\end{array}$ & $\begin{array}{l}41.6 \% \text { ( } 35.9 \% \text { of females and } 47.4 \% \text { of males) had gambled offline or online and } 9.4 \% \text { had } \\
\text { gambled online in the past } 3 \text { months ( } 3.7 \% \text { of females and } 15.3 \% \text { of males). Online gamblers } \\
\text { were more likely than offline gamblers to engage in multiple forms of gambling, and they scored } \\
\text { proportionally more frequently "high" or "low to moderate" in problem gambling severity }\end{array}$ \\
\hline $\begin{array}{l}\text { Rossen et al } \\
(2016)^{78}\end{array}$ & $\begin{array}{l}\mathrm{N}=8,500 \text { New Zealanders, } \\
\text { secondary school students }\end{array}$ & $\begin{array}{l}24.2 \% \text { of students had gambled in the last year, and } 4.8 \% \text { had two or more indicators of } \\
\text { unhealthy gambling. Unhealthy gambling was associated with more accepting attitudes toward } \\
\text { gambling, gambling via gambling machines/casinos/track betting, being worried about and/or } \\
\text { trying to cut down on gambling and having attempted suicide }\end{array}$ \\
\hline $\begin{array}{l}\text { Anagnostopoulos } \\
\text { et al }(2017)^{79}\end{array}$ & $\begin{array}{l}\text { 2,141 Greek high-school } \\
\text { students, representative } \\
\text { sample from the capital of } \\
\text { Athens }\end{array}$ & $\begin{array}{l}\text { One-year prevalence of high-severity problem gambling was found to be } 5.6 \% \text {. Male gender, } \\
\text { parental engagement with gambling activities, living without the parents, low grades at school, } \\
\text { foreign nationality, and the referent absence of availability of food in the household increased } \\
\text { the risk of problem gambling }\end{array}$ \\
\hline $\begin{array}{l}\text { Gonzalez-Roz et al } \\
(2017)^{80}\end{array}$ & $\begin{array}{l}\text { I,3 } 13 \text { Spanish adolescents, } \\
\text { aged } 14-18 \text { years }\end{array}$ & $\begin{array}{l}\text { At-risk and problem gambling was } 4 \% \text { and } I .2 \% \text {, respectively. Having a relative with gambling } \\
\text { problems predicted at-risk gambling. Both living with only one parent, or not living with } \\
\text { parents at all, and playing on electronic gambling machines in the last year were associated with } \\
\text { problem gambling }\end{array}$ \\
\hline Huic et al $(2017)^{81}$ & $\begin{array}{l}\text { I,372 Croatian high-school } \\
\text { girls }\end{array}$ & $\begin{array}{l}7.4 \% \text { were considered regular gamblers, and out of those who gambled at least once in their } \\
\text { lifetime }(n=862), । I .2 \% \text { already experienced mild adverse consequences because of their } \\
\text { gambling (at-risk gamblers), with } 3.2 \% \text { experiencing serious consequences (problem gamblers) }\end{array}$ \\
\hline
\end{tabular}

regulate. Commercial online gambling includes similar forms of gambling as to what one may find outside the online environment, including online casinos, online games of chance and card games, and lotteries, where there is a clear promise of monetary gain from gambling a sum of money. Simulated gambling includes all those aforementioned forms of gambling but without the monetary gain. ${ }^{27}$ Still the subject may experience those forms of gambling in the same way and may opt to spend an amount of money in order to gain some sort of perceived advantage over the co-players or adversaries. This advantage may be a higher chance of win or the chance to play for a longer period of time. Hence indirectly, the subject may in fact spend funds in order to gain some sort of perceived value, which does associate with the notion of spending funds in order to gain money but is not, for the time being, regulated. 
The link between simulated gambling and commercial gambling is clearly demonstrated by the fact that $\sim 20 \%$ of adults and adolescents who play simulated gambling games move to online commercial gambling, while $16 \%$ of adults and $25 \%$ of adolescents reported moving from commercial to simulated gambling. ${ }^{28}$ Those who moved from simulated to commercial gambling did so in an attempt to win money, while those who moved from commercial to simulated gambling consciously chose to as a way to avoid spending money. The first pathway, from simulated to commercial gambling, comes as a result of the individual effectively practicing his skills, while being constantly behaviorally rewarded for winning, with various forms of gratification that include in-game bonuses, rank levels, etc. In this environment, the gambler is shielded from any negative consequences since the loss does not incur any significant disadvantage. Inflated chances of win and payout foster a false belief in the player's gambling efficacy, while deflating the perceived sense of risk. ${ }^{5,29-32}$ Those simulated gambling opportunities may casually appear in social media and propagate through a network of contacts employing direct or indirect advertising. ${ }^{6}$ An alarming fact is that simulated gambling opportunities are not restricted to "clear-cut" instances of gambling-like activities; simulated gambling may appear, for example, as a game-within-a-game where the player of a video game has to engage in some form of gambling to advance his character story or for recreation. The most famous of those instances was the case of online casinos propagating within the online game "Second Life", leading to an FBI-sanctioned ban on in-world gambling and all wagering on games of chance or games that rely on the outcome of real-life-organized sporting events when they provide a payout in either the in-game currency or a real-life currency. ${ }^{33}$

The pressing issue to investigate is whether simulated gambling is an etiological factor in gambling involvement with actual funds and, subsequently, problem gambling. A study of 1,220 adolescents attempted to monitor the progression from simulated gambling to gambling with real money using a longitudinal design with a one-year interval period. ${ }^{34}$ At the second measurement time, $28.8 \%$ of the participants had gambled for the first time with real money. Logistic regressions revealed that the predictive association between simulated gambling and gambling with real money only holds for adolescents who transitioned from simulated poker to poker with real money. Clearly, different gambling genres have varying trajectories of potential crossover between simulated and actual gambling. Interestingly, when questioned as to the motives for engaging in simulated gambling, while one out of three players reported that they play so as to avoid spending money, a small minority of gamblers (7.2\%) reported that they gamble in this way so as to reduce the real-life gambling practices. ${ }^{28}$ Thus, we clearly have several potential gamblers with money and a number of gamblers who are trying to reign in their behavior.

Qualitative research on player attitudes in online games of chance also reveals parallels to instances of gambling with real money. A "micro-transaction" is an in-game purchase of relatively small monetary value that seemingly offers disproportionately larger value within the game itself; e.g., a small fee of \$1 (USD) may be the equivalent of a thousand credits in the in-game currency. A player may enter the game with an initial free sum of in-game currency and play without the added benefit of a micro-transaction but is constantly reminded of either special bonuses and possibilities that will be available after very long hours of play or a fee through a micro-transaction. Social casino gamers who engaged in micro-transactions reported significantly higher levels of impulsivity, reward sensitivity, and problem gambling severity, but not competitiveness. ${ }^{35}$ In terms of motivation to make micro-transactions, desire to extend play was endorsed most frequently, followed by a desire to access additional features, chasing lost credits, and to speed up play. Lastly, among participants who made micro-transactions, reward sensitivity predicted making micro-transactions to chase lost credits.

Recently there has been a flurry of instances where mainstream online video games, with player goals unrelated to gambling (e.g., driving or combat simulations), have included a reward system for the player that provides random gains in exchange for "points" gathered either by long hours of gameplay or by direct pay to the gaming company. ${ }^{36}$ Effectively the player is offered a gambling opportunity that costs him either time or money while rewarding him with in-game bonuses of value to him. This trend started out inconspicuously more than ten years ago with players offered in-game rewards for their actions ${ }^{37}$ and now draws parallels to the random nature of gain in the slot machines and related commercial gambling. Recreational video game playing and online gambling have a high degree of co-occurrence in the preferred adolescent online activities, as shown in a 2013 study by Floros et al where video game playing increased in frequency in parallel with the increase in the severity of online gambling problem behavior. ${ }^{38}$ In a 2017 study, McBride and Derevensky examined the parallels between gambling and video game playing behavior among 1,229 adolescents and young adults. ${ }^{39}$ Results indicated that gamblers, relative to non-gamblers, were more likely to play video games and video game players 
were more likely than nonplayers to gamble. Both social and problem gamblers had higher rates of video game playing than did non-gamblers, and addicted gamers had higher rates of gambling than did social and non-gamers. Those findings indicate that intermingling gambling-like rewards into online games otherwise unrelated to gambling may lead to an unseen danger of extending one behavior to another. More research is urgently needed on this thorny issue.

\section{Risk and protective factors for adolescent gambling}

A main goal of all prevalence studies is to establish possible risk and protective factors for the studied issue. Population studies have thus highlighted several risk factors for adolescent problem gambling, including male gender, early time of onset, innate psychological traits, relative parental practices, and comorbid mental health issues. ${ }^{9,12,24,40}$ Unfortunately, the clinical importance of those correlations remained unclear since correlation does not necessarily imply causation, and variables that are commonly associated with gambling may not be in fact predictive of moderating or mediating gambling behaviors. A recent meta-analysis of published studies $^{41}$ calculated effect sizes for those distinct factors by way of Stouffer's method of testing the combined significance level of the associations in combination with meta-analytic methodology. Small effect sizes were observed for tobacco use, alcohol and cannabis use, illicit drug use, antisocial behaviors and violence, sensation seeking, and depressive symptoms. Small to medium effect sizes were evident for impulsivity, undercontrolled temperament, and higher number of gambling activities, while a medium effect size was found for male gender and poor academic performance. A strong mean effect size for the development of problem gambling was only found for gambling problem severity. A large number of reported risk factors for the development of subsequent problem gambling behavior were in fact rejected by both Stouffer's method and meta-analysis, including activation control, aggression, anxiety symptoms, attention problems, a big early gambling win, dispositional attention, psychological distress (including internalizing symptoms), religious attendance, and suicidal ideation at the first evaluation. Furthermore, a number of factors including age, early gambling onset, negative affect, safety-related risk taking, sexual risk taking, and big early gambling loss were rejected by the more stringent meta-analyses and supported only by Stouffer's method. Those results demonstrate that while certain behavioral characteristics are associated with problem gambling behavior, they are not necessarily key to predicting the onset of this behavior but rather hallmarks in its subsequent evolution; a patient, for example, may or may not have had a first big win before the onset of pathological engagement with gambling, despite the fact that this event subsequently is recalled as a hallmark following a targeted inquiry by a clinician.

With regard to protective factors, parent supervision and socioeconomic status reported at the first evaluation were significantly negatively associated with subsequent problem gambling, with current social problems also supported by meta-analysis but not by Stouffer's method. In all three cases, mean effect sizes were small.

\section{Adolescent neurobiological susceptibility to gambling}

Adolescents are apparently prone to seeking out gambling experiences due to differences in neurobiology, when compared to adults. Adolescents evidenced less recruitment of the right ventral striatum and right-extended amygdala while anticipating responding for gains (in contrast with anticipation of non-gains) compared with young adults. ${ }^{42}$ The subcortical neural systems in adolescents are the first ones to mature and are disproportionately activated relative to later maturing top-down control systems, leading to an adolescent biasing toward immediate gains rather than long-term ones, ${ }^{43}$ evidenced in less engagement of prefrontal regulatory structures when making risky economic choices. ${ }^{44}$ Compared to adults, the adolescent amygdale is activated more easily from reward cues and is less sensitive to potential harm. ${ }^{45}$ Developmental factors may also weigh in, as Gerra et al have suggested that childhood experience of neglect and poor parent-child attachment may partially contribute to a complex neurobiological derangement including hypothalamic-pituitary-adrenal axis and dopamine system dysfunctions, further exacerbating the tendency to favor reward cues. ${ }^{46}$

\section{Reported motives for gambling}

Moving from population data to the level of individual cognitions and beliefs, there is significant variability as to the underlying motivations implicated with entry into gambling, increased involvement, and continued gambling, in spite of negative consequences brought from repeated losses. Although the obvious initial motive is related to the perceived profits from winning, studies of established gamblers converge on three distinct sets of motivations unrelated to monetary gains: enhancement, coping, and social motives. ${ }^{47}$ Those gamblers with high levels of enhancement and coping motives gamble to regulate emotional states. Gamblers with 
high levels of enhancement motives are also characterized by high levels of sensation seeking and impulsivity, and gamble for the "high" - those feelings of excitement that gambling can create. On the other hand, gamblers with high levels of coping motives are characterized by increased levels of depression, anxiety, and neuroticism, and gamble as a maladaptive way to escape these negative emotional states. Gamblers with high levels of social motives do not gamble to regulate their emotions since they are generally free of comorbid psychopathology and maladaptive personality traits, but instead gamble for social affiliation.

In agreement with the theory and findings from adult gamblers, a recent study in college students found that only high enhancement motives for gambling were particularly predictive of problem gambling. ${ }^{48}$ Similarly, a study by Canale et $\mathrm{al}^{49}$ aimed to clarify whether motives mediate the relationship between inherent traits, such as impulsivity and difficulty in self-regulating, to gambling; results indicated that those who tend to act rashly in response to extremely positive moods showed higher enhancement and coping motives, which in turn were positively related to gambling problems. Individuals with higher levels of sensation seeking were more likely to have higher levels of enhancement motives, which in turn were also positively related to gambling problems.

\section{Psychiatric comorbidity in adolescent gambling}

As early as 1998, a number of studies started demonstrating considerable comorbidity of gambling, delinquency, and both licit and illicit drug use; in a sample of 4,516 adolescents aged 11-16 years, results indicated that adolescent gamblers, when compared with non-gamblers, were significantly more likely to drink alcohol, smoke tobacco, and take illicit drugs. ${ }^{50}$ Adolescent students in Ohio who reported problem gambling behaviors showed increased substance abuse, various mental issues, and delinquency/criminal problems that are similar to those seen among adult problem gamblers. The odds of problem gambling youth reporting mental distress was 4.2 times higher than the rest of the sample and the odds of problem gamblers reporting a suicide attempt were 17.8 times greater than the rest of the sample. ${ }^{51}$ Data from a cross-sectional questionnaire survey of a stratified, random sample of 4,734 high-school students aged 12-23 years in Hong Kong showed that gambling significantly correlated with tobacco use, alcohol use, and delinquent acts. ${ }^{52}$ However, caution is required with those associations, as it has been pointed out ${ }^{11,53}$ that gambling and substance abuse may be common developmental experiences in a shared pathway attributed to socioeconomic adversities or shared personality attributes like impulsivity.

Evidence regarding other psychiatric comorbidities with gambling in adolescence are scarce. In a sample of 1,044 high-school students, probable pathological gamblers reported more daily and weekly alcohol consumption, used illicit drugs, and smoked more cigarettes on a daily basis compared with non-gamblers, social gamblers, and at-risk gamblers for serious problems. Probable pathological gamblers similarly reported higher levels of state anxiety, trait anxiety, and social stress compared with non-gamblers, social gamblers, and at-risk gamblers. Adolescents with the highest state and trait anxiety scores had more severe gambling and substance abuse problems. ${ }^{54}$

\section{Prevention and treatment challenges}

Given that there is significant prevalence for adolescent problem gambling and numerous adverse effects associated with it, prevention and treatment efforts have become even more important for this age group. A choice has to be made between abstinence and harm reduction as to the prevention and treatment model that will be followed. Abstinence-based programs place emphasis on the notion that underage youth are legally prohibited from access, including the purchase of lottery products, and as such should not engage in these behaviors. On the other hand, a harm reduction approach supports strategies that aim to reduce harmful negative consequences incurred through involvement in risky behaviors. ${ }^{55}$ Choosing between those two approaches is often a matter of political debate; however, one has to point out that it is not realistic to expect from adolescents to cease engaging in a risky behavior that is so widespread among peers. Thus, reducing the immediate harmful consequences of involvement in gambling activities, along with other risky adolescent behaviors, appears to be a more feasible aim. The end goal is for the adolescent to become an informed, analytic consumer whose choice to participate in risky activities will pose potentially fewer problematic behaviors, and this can be applied to all aforementioned risky behaviors. A natural choice for the implementation of prevention programs would be the school environment. A recent meta-analysis ${ }^{56}$ of twenty papers presenting school-based gambling education programs found that only nine of the studies attempted to measure intervention effects on behavioral outcomes, with only five of those reporting significant changes in gambling behavior but with several methodological inadequacies. More 
standardization following rigorous review of those programs is clearly required here as well.

From a treatment perspective, the harm reduction paradigm implies the promotion of low-threshold access to services in which realistically achievable goals take priority for those adolescents who cannot be expected to cease a particular risky behavior. ${ }^{57}$ This recommendation does not apply to established/disordered gamblers who may be seeking treatment and are typically older or may have gone through harm reduction approaches without success in the past, as they were less motivated for change.

Currently, there is no empirically validated treatment program available for adolescent problem gamblers worldwide ${ }^{58}$ however, there have been reported successes with cognitive-behavioral-based programs, ${ }^{59,60}$ since cognitive distortions associated with gambling are a powerful predictor of gambling severity in adolescents, ${ }^{61}$ although cognitive restructuring apparently has not yet been adapted to address the maladaptive cognitions implicit in skill game players. ${ }^{62}$ The paucity of data on pharmacological interventions is disconcerting, since there are no studies investigating the safety and efficacy of pharmacological treatments for pathological gambling in adolescents. ${ }^{63} \mathrm{~A}$ major hurdle is that adolescent problem gamblers are very reluctant to seek treatment or formal assistance, ${ }^{59,64}$ greatly limiting the number of those seeking specific help in a specialized treatment facility at any point in time. By the time adolescent gamblers are willing to seek treatment, they usually start to experience significant family, social, academic, and legal difficulties. Additionally young gamblers often present with a significant number and variety of comorbid psychological disorders, and their treatment may thus be handled according to their presenting complaint, developmental stage, and therapist's particular orientation. ${ }^{58}$ These practical issues have led to the proposal of implementing and evaluating non-traditional intervention strategies such as different tools of Internet-based support. ${ }^{59}$ Gambling may be best conceptualized in clinical practice as one risky adolescent behavior with potentially serious negative consequences. ${ }^{55}$ Organizing a treatment protocol with this premise may increase the target population and uncover comorbidities with other forms of risky behaviors that have been associated with gambling, as are drug and alcohol consumption, delinquency, risky sexual behavior, and addictive video game playing. ${ }^{65,66}$ Since adolescent motivation to enter therapy and follow a long treatment protocol is low, there is room for employing brief, accessible interventions (such as motivational interviewing, personalized feedback interventions, and web-based online services) that may be efficacious for the treatment of problem gambling among adolescents and emerging adults, although relevant results have not been replicated or validated as to their long-term efficacy. ${ }^{67}$

\section{Conclusion and suggestions for future research}

Although more than twenty years have elapsed since the early research reports on adolescent gambling, there has been little progress in the standardization of prevention and treatment efforts. There is a large body of research available that clearly demonstrates the extent of the issue with PG and its negative impact on those affected; however, little attention has been devoted to the technological evolution leading to a host of unregulated gambling opportunities, either with real or simulated funds, or with other notions of value to the gambler who may not even identify himself as being a gambler.

We may be drawing toward regulation of those cases based not on direct monetary incentive but on perceived value to the player. Gambling is a behavior that operates on a "random ratio" (RR) schedule of reinforcement with physiological arousal occurring on average after a prespecified number of gambles but with a variable number of intervening trials between wins. ${ }^{68}$ We need to extend the definition of gambling to include not only monetary incentives but also handouts of value relative to that particular gambling environment, as long as the RR schedule of reinforcement is evident. Up to this point in time, gambling that did not involve a direct monetary incentive did not feature in the standard definition, despite the established fact that perceived monetary gain is not a sufficient factor in the establishment and, particularly, in the maintenance of problem gambling behavior. Longitudinal studies of those adolescents that are active with simulated gambling and other forms of gambling-like behaviors are needed, but what is sorely lacking is some form of clear regulation on what is and what is not harmful in long term to the adolescent psyche.

\section{Disclosure}

The author reports no conflicts of interest in this work.

\section{References}

1. Lesieur HR, Klein R. Pathological gambling among high school students. Addict Behav. 1987;12(2):129-135.

2. National Research Council. Pathological Gambling: A Critical Review. Washington, DC: National Academies Press; 1999.

3. Derevensky JL, Gainsbury SM. Social casino gaming and adolescents: should we be concerned and is regulation in sight? Int J Law Psychiatry. 2016;44:1-6.

4. Griffiths MD, Parke J. Adolescent gambling on the Internet: a review. Int $J$ Adolesc Med Health. 2010;22(1):59-75. 
5. James RJ, O'malley C, Tunney RJ. Understanding the psychology of mobile gambling: a behavioural synthesis. Br J Psychol. 2017;108(3):608-625.

6. Jacques C, Fortin-Guichard D, Bergeron P-Y, Boudreault C, Lévesque D, Giroux I. Gambling content in Facebook games: a common phenomenon? Comput Human Behav. 2016;57:48-53.

7. King DL, Delfabbro PH. Early exposure to digital simulated gambling: a review and conceptual model. Comput Human Behav. 2016;55:198-206.

8. American Psychiatric Association. Diagnostic and Statistical Manual of Mental Disorders (DSM-5®). American Psychiatric Association Publishing: Arlington, VA, USA; 2013.

9. Delfabbro P, King DL, Derevensky JL. Adolescent gambling and problem gambling: prevalence, current issues, and concerns. Curr Addict Rep. 2016;3(3):268-274.

10. Hardoon KK, Gupta R, Derevensky JL. Psychosocial variables associated with adolescent gambling. Psychol Addict Behav. 2004;18(2):170-179.

11. Winters KC, Anderson N. Gambling involvement and drug us among adolescents. J Gambl Stud. 2000;16(2):175-198.

12. Hardoon KK, Gupta R, Derevensky JL. Psychosocial variables associated with adolescent gambling. Psychol Addict Behav. 2004;18(2):170-179.

13. Dussault F, Brendgen M, Vitaro F, Carbonneau R, Boivin M, Tremblay RE. Co-morbidity between gambling problems and depressive symptoms: a longitudinal perspective of risk and protective factors. $J$ Gambl Stud. 2016;32(2):547-565.

14. Mutti-Packer S, Hodgins DC, el-Guebaly N, et al. Problem gambling symptomatology and alcohol misuse among adolescents: a parallel -process latent growth curve model. Psychol Addict Behav. 2017;31(4):447.

15. Yeoman T, Griffiths $\mathrm{M}$. Adolescent machine gambling and crime. $J$ Adolesc. 1996;19(1):99-104.

16. Winters KC, Stinchfield RD, Fulkerson J. Toward the development of an adolescent gambling problem severity scale. J Gambl Stud. 1993;9(1):63-84.

17. Fisher S. Measuring pathological gambling in children: the case of fruit machines in the UK. J Gambl Stud. 1992;8(3):263-285.

18. Johnson EE, Hamer R, Nora RM, Tan B, Eisenstein N, Engelhart C. The Lie/Bet Questionnaire for screening pathological gamblers. Psychol Rep. 1997;80(1):83-88.

19. Tremblay J, Stinchfield R, Wiebe J, Wynne H. Canadian Adolescent Gambling Inventory (CAGI) Phase III Final Report. Alberta Gaming Research Institute: Alberta, Canada; 2010.

20. Gamblers Anonymous. 3rd ed. Los Angeles, CA: Gamblers Anonymous Publishing; 1984.

21. Griffiths M. Internet gambling: issues, concerns, and recommendations. Cyberpsychol Behav. 2003;6(6):557-568.

22. Derevensky JL, Gupta R. Internet gambling amongst adolescents: a growing concern. Int J Ment Health Addict. 2007;5(2):93-101.

23. Raylu N, Oei TP. Role of culture in gambling and problem gambling. Clin Psychol Rev. 2004;23(8):1087-1114.

24. Molinaro S, Canale N, Vieno A, et al. Country-and individual-level determinants of probable problematic gambling in adolescence: a multi-level cross-national comparison. Addiction. 2014;109(12): 2089-2097.

25. Ellenbogen S, Gupta R, Derevensky JL. A cross-cultural study of gambling behaviour among adolescents. J Gambl Stud. 2007;23(1): 25-39.

26. Prensky M. Digital natives, digital immigrants part 1. On the Horiz. 2001;9(5):1-6.

27. King DL, Delfabbro PH, Kaptsis D, Zwaans T. Adolescent simulated gambling via digital and social media: an emerging problem. Comput Human Behav. 2014;31:305-313.

28. Gainsbury S, King D, Abarbanel B, Delfabbro P, Hing N. Convergence of Gambling and Gaming in Digital Media. Melbourne, VIC: Victorian Responsible Gambling Foundation; 2015.

29. Mcbride J, Derevensky J. Internet gambling and risk-taking among students: an exploratory study. $J$ Behav Addict. 2012;1(2):50-58.
30. Gupta R, Derevensky J, Wohl M. A qualitative examination of online gambling culture among college students: factors influencing participation, maintenance and cessation. Paper presented at: International Conference on Gambling and Risk Taking; Las Vegas; Nevada, May 27-31, 2013.

31. Bednarz J, Delfabbro P, King D. Practice makes poorer: practice gambling modes and their effects on real-play in simulated roulette. Int $J$ Ment Health Addict. 2013;11(3):381-395.

32. Frahn T, Delfabbro P, King DL. Exposure to free-play modes in simulated online gaming increases risk-taking in monetary gambling. J Gambl Stud. 2015;31(4):1531-1543.

33. Kaplan AM, Haenlein M. The fairyland of Second Life: virtual social worlds and how to use them. Bus Horiz. 2009;52(6):563-572.

34. Dussault F, Brunelle N, Kairouz S, et al. Transition from playing with simulated gambling games to gambling with real money: a longitudinal study in adolescence. Int Gambl Stud. 2017;17(3):386-400.

35. Kim HS, Hollingshead S, Wohl MJ. Who spends money to play for free? Identifying who makes micro-transactions on social casino games (and why). J Gambl Stud. 2017;33(2):525-538.

36. Machkovech S. Loot boxes have reached a new low with Forza 7's "pay to earn" option. Ars Technica. 2017. Available from: https://arstechnica. com/gaming/2017/09/loot-boxes-have-reached-a-new-low-with-forza7s-pay-to-earn-option/. Accessed November 19, 2017.

37. Griffiths M. Convergence of gambling and gaming: implications. World Online Gambl Law Rep. 2008;7(2):12-13.

38. Floros GD, Siomos K, Fisoun V, Geroukalis D. Adolescent online gambling: the impact of parental practices and correlates with online activities. J Gambl Stud. 2013;29(1):131-150.

39. McBride J, Derevensky J. Gambling and video game playing among youth. J Gambl Issues. 2017;(34):156-178.

40. Volberg RA, Gupta R, Griffiths MD, Ólason DT, Delfabbro P. An international perspective on youth gambling prevalence studies. Int $J$ Adolesc Med Health. 2010;22(1):3-38.

41. Dowling N, Merkouris S, Greenwood C, Oldenhof E, Toumbourou J, Youssef G. Early risk and protective factors for problem gambling: a systematic review and meta-analysis of longitudinal studies. Clin Psychol Rev. 2017;51:109-124.

42. Bjork JM, Knutson B, Fong GW, Caggiano DM, Bennett SM, Hommer DW. Incentive-elicited brain activation in adolescents: similarities and differences from young adults. J Neurosci. 2004;24(8):1793.

43. Galvan A, Hare TA, Parra CE, et al. Earlier development of the accumbens relative to orbitofrontal cortex might underlie risk-taking behavior in adolescents. $J$ Neurosci. 2006;26(25):6885.

44. Eshel N, Nelson EE, Blair RJ, Pine DS, Ernst M. Neural substrates of choice selection in adults and adolescents: development of the ventrolateral prefrontal and anterior cingulate cortices. Neuropsychologia. 2007;45(6):1270-1279.

45. Ernst M, Nelson EE, Jazbec S, et al. Amygdala and nucleus accumbens in responses to receipt and omission of gains in adults and adolescents. Neuroimage. 2005;25(4):1279-1291.

46. Gerra G, Leonardi C, Cortese E, et al. Childhood neglect and parental care perception in cocaine addicts: relation with psychiatric symptoms and biological correlates. Neurosci Biobehav Rev. 2009;33(4):601-610.

47. Milosevic A, Ledgerwood DM. The subtyping of pathological gambling: a comprehensive review. Clin Psychol Rev. 2010;30(8):988-998.

48. Lambe L, Mackinnon SP, Stewart SH. Validation of the gambling motives questionnaire in emerging adults. J Gambl Stud. 2015;31(3):867-885.

49. Canale N, Vieno A, Griffiths MD, Rubaltelli E, Santinello M. How do impulsivity traits influence problem gambling through gambling motives? The role of perceived gambling risk/benefits. Psychol Addict Behav. 2015;29(3):813.

50. Griffiths M, Sutherland I. Adolescent gambling and drug use. J Community Appl Soc Psychol. 1998;8(6):423-427.

51. Cook S, Turner NE, Ballon B, et al. Problem gambling among Ontario students: associations with substance abuse, mental health problems, suicide attempts, and delinquent behaviours. J Gambl Stud. 2015;31(4): 1121-1134. 
52. Cheung NWT. Low self-control and co-occurrence of gambling with substance use and delinquency among Chinese adolescents. J Gambl Stud. 2014;30(1):105-124.

53. Griffiths M, Parke J, Wood R. Excessive gambling and substance abuse: is there a relationship? J Subst Use. 2002;7(4):187-190.

54. Ste-Marie C, Gupta R, Derevensky JL. Anxiety and social stress related to adolescent gambling behavior and substance use. J Child Adolesc Subst Abuse. 2006;15(4):55-74.

55. Dickson LM, Derevensky JL, Gupta R. Harm reduction for the prevention of youth gambling problems: lessons learned from adolescent high-risk behavior prevention programs. J Adolesc Res. 2004;19(2):233-263.

56. Keen B, Blaszczynski A, Anjoul F. Systematic review of empirically evaluated school-based gambling education programs. J Gambl Stud. 2017;33(1):301-325.

57. Derevensky JL, Gupta R. Adolescents with gambling problems: a synopsis of our current knowledge. J Gambl Issues. 2004(10).

58. Gupta R, Derevensky JL. A treatment approach for adolescents with gambling problems.Gambling Problems in Youth. Springer: Cham, Switzerland; 2005:165-188.

59. Hayer T, Griffiths MD. Gambling. In: Gullotta TP, Plant RW, Evans M, editors. Handbook of Adolescent Behavioral Problems: Evidence-Based Approaches to Prevention and Treatment. Springer: Cham, Switzerland 2015:539-558.

60. Ladouceur R, Boisvert J-M, Dumont J. Cognitive-behavioral treatment for adolescent pathological gamblers. Behav Modif. 1994;18(2):230-242.

61. Cosenza M, Nigro G. Wagering the future: cognitive distortions, impulsivity, delay discounting, and time perspective in adolescent gambling. J Adolesc. 2015;45:56-66.

62. Chrétien M, Giroux I, Goulet A, Jacques C, Bouchard S. Cognitive restructuring of gambling-related thoughts: a systematic review. Addict Behav. 2017;75(Suppl C):108-121.

63. Grant JE, Potenza MN. Adolescent problem gambling: pharmacological treatment options. Youth Gambling: The Hidden Addiction: Walter de Gruyter, Berlin, Germany; 2011.

64. Hardoon K, Derevensky JL, Gupta R. Empirical measures vs. perceived gambling severity among youth: why adolescent problem gamblers fail to seek treatment. Addict Behav. 2003;28(5):933-946.

65. Griffiths M, Wood RT. Risk factors in adolescence: the case of gambling, videogame playing, and the Internet. J Gambl Stud. 2000;16(2):199-225.

66. Vitaro F, Brendgen M, Ladouceur R, Tremblay RE. Gambling, delinquency, and drug use during adolescence: mutual influences and common risk factors. J Gambl Stud. 2001;17(3):171-190.

67. St-Pierre R, Derevensky JL. Youth gambling behavior: novel approaches to prevention and intervention. Curr Addict Rep. 2016;3(2):157-165.
68. Dickerson MG. Compulsive Gamblers. Addison-Wesley Longman Ltd: Boston, MA, USA; 1984.

69. Wong ILK, So EMT. Internet gambling among high school students in Hong Kong. J Gambl Stud. 2014;30(3):565-576.

70. Lee GP, Martins SS, Pas ET, Bradshaw CP. Examining potential school contextual influences on gambling among high school youth. Am J Addict. 2014;23(5):510-517.

71. Castrén S, Grainger M, Lahti T, Alho H, Salonen AH. At-risk and problem gambling among adolescents: a convenience sample of first-year junior high school students in Finland. Subst Abuse Treat Prev Policy. 2015;10(1):9.

72. Floros G, Paradisioti A, Hadjimarcou M, Mappouras DG, Karkanioti O, Siomos K. Adolescent online gambling in Cyprus: associated school performance and psychopathology. J Gambl Stud. 2015;31(2):367-384.

73. Hanss D, Mentzoni RA, Blaszczynski A, Molde H, Torsheim T, Pallesen $\mathrm{S}$. Prevalence and correlates of problem gambling in a representative sample of Norwegian 17-year-olds. J Gambl Stud. 2015;31(3):659-678.

74. Räsänen T, Lintonen T, Konu A. Gambling and problem behavior among 14-to 16-year-old boys and girls in Finland. J Gambl Issues. 2015;31:1-23.

75. Fröberg F, Rosendahl IK, Abbott M, Romild U, Tengström A, Hallqvist $\mathrm{J}$. The incidence of problem gambling in a representative cohort of Swedish female and male 16-24 year-olds by socio-demographic characteristics, in comparison with 25-44 year-olds. J Gambl Stud. 2015;31(3):621-641.

76. Canale N, Griffiths MD, Vieno A, Siciliano V, Molinaro S. Impact of Internet gambling on problem gambling among adolescents in Italy: findings from a large-scale nationally representative survey. Comput Human Behav. 2016;57:99-106.

77. Elton-Marshall T, Leatherdale ST, Turner NE. An examination of internet and land-based gambling among adolescents in three Canadian provinces: results from the youth gambling survey (YGS). BMC Public Health. 2016;16(1):277.

78. Rossen FV, Clark T, Denny SJ, et al. Unhealthy gambling amongst New Zealand secondary school students: an exploration of risk and protective factors. Int J Ment Health Addict. 2016;14(1):95-110.

79. Anagnostopoulos DC, Lazaratou H, Paleologou MP, et al. Adolescent gambling in greater Athens area: a cross-sectional study. Soc Psychiatry Psychiatr Epidemiol. 2017;52(11):1345-1351.

80. González-Roz A, Fernández-Hermida JR, Weidberg S, Martínez-Loredo V, Secades-Villa R. Prevalence of problem gambling among adolescents: a comparison across modes of access, gambling activities, and levels of severity. J Gambl Stud. 2017;33(2):371-382.

81. Huic A, Hundric DD, Kranzelic V, Ricijas N. Problem gambling among adolescent girls in Croatia - the role of different psychosocial predictors Front Psychol. 2017;8:792.
Adolescent Health, Medicine and Therapeutics

\section{Publish your work in this journal}

Adolescent Health, Medicine and Therapeutics is an international, peer-reviewed, open access journal focusing on health, pathology, and treatment issues specific to the adolescent age group. All aspects of health maintenance, preventative measures and disease treatment interventions are addressed within the journal and practitioners from all disciplines are
Dovepress

invited to submit their work as well as healthcare researchers and patient support groups. This journal is included in PubMed. The manuscript management system is completely online and includes a very quick and fair peer-review system. Visit http://www.dovepress.com/testimonials. php to read real quotes from published authors. 